\title{
CORRECTION
}

\section{Correction to: Microbial-Induced Desaturation in Stratified Soil Conditions}

\author{
Elizabeth G. Stallings Young ${ }^{1} \cdot$ Nariman Mahabadi $^{2} \cdot$ Claudia E. Zapata $^{1} \cdot$ Leon A. Van Paassen ${ }^{1}$ (])
}

Published online: 19 June 2021

(c) The Author(s), under exclusive licence to Springer Nature Switzerland AG 2021

\section{Correction to: \\ International Journal of Geosynthetics and Ground \\ Engineering (2021) 7:37 \\ https://doi.org/10.1007/s40891-021-00276-9}

In the original publication of the article, Fig. 8 was published with an error. Figure 8 was not included and instead Fig. 9 was included twice.

The correct Fig. 8 is given in this correction.

Original article has been updated.

The original article can be found online at https://doi.org/10.1007/ s40891-021-00276-9.

Leon A. Van Paassen

Leon.Vanpaassen@asu.edu

Elizabeth G. Stallings Young

egstalli@asu.edu

1 School of Sustainable Engineering and the Built Environment, Arizona State University, Tempe, AZ 85287, US

2 Department of Civil Engineering, University of Akron, Akron, OH 44321, US 


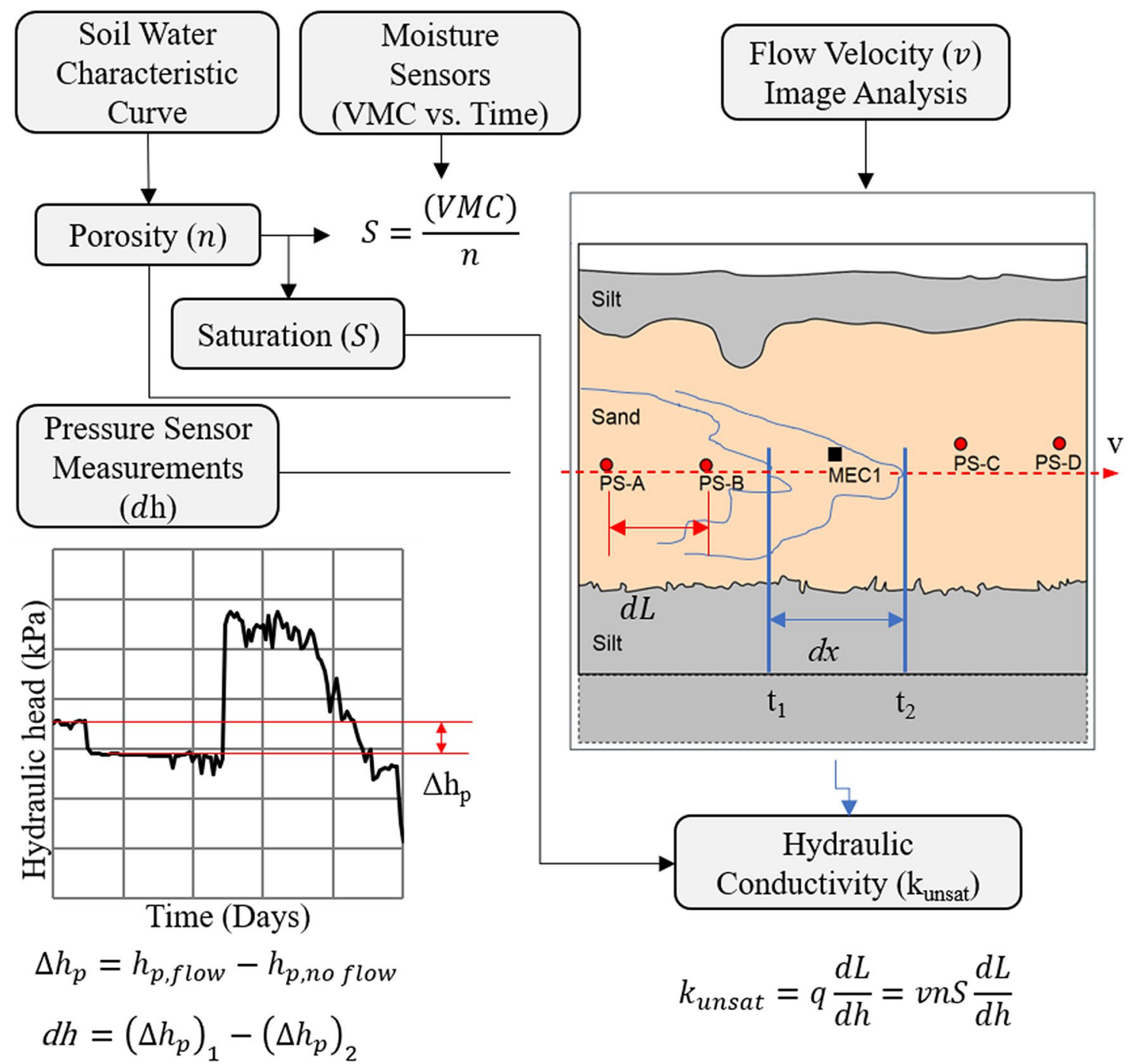

Fig. 8 Process for determining unsaturated permeability, through combination of various measurements

Publisher's Note Springer Nature remains neutral with regard to jurisdictional claims in published maps and institutional affiliations. 